\title{
ПРАВА АРЕНДАТОРА ПРИ ЗАКЛЮЧЕНИИ ДОГОВОРА АРЕНДЫ ЗЕМЕЛЬНОГО УЧАСТКА В РФ: НЕКОТОРЫЕ АСПЕКТЫ
}

\begin{abstract}
Аннотация: Предметом исследования вопроса прав арендатора являются правоотношения, связанные с предоставлением преимущественного права арендатора на заключение договора аренды на новый срок, регулирующийся ст. 621 ГК РФ и ст. 22 ЗК РФ, а также право застройки, которое неоднократно рассматривается и изменяется правоведами и носит до сих пор дискуссионный характер. Данные правоотношения носят смешанный характер, так как кроме гражданского и земельного законодательства данные права регулируются законодательством о конкуренции и иными нормативными правовыми актами. Методологическую основу настоящей работы составляют: общенаучные методь - анализ, синтез, абстрагирование, сравнение, классификация; специальные юридчческие - аналогия, толкование, критический анализ, обзор правовых актов. Данная статья посвящена институту аренды земельных участков, а именно отдельному его аспекту. К таким относятся права арендатора: преимущественное право на заключение договора аренды на новый срок и право владения и пользования чужим земельным участком в целях возведения на нем здания или сооружения и его последующей эксплуатации (право застройки). Эти права в настоящее время имеют немаловажное значение в связи с изменениями, которые происходят в гражданском законодательстве РФ.

Abstract: The subject of the research on the rights of the tenant become the legal relations pertaining to the priority right given to the tenant to be able to extend the term of the lease as regulated by the article 621 of the Civil Code of the Russian Federation and the article 22 of the Land Code of the Russian Federation. This includes the right to build, which has been numerously reviewed and changed by the legislators and still carries a debatable character. These legal relations have mixed nature, as in addition to the Civil and Land legislation these rights are also regulated by the legislation on competition, as well as other normative legal acts. This article is dedicated to the institution of land leasing, namely to a separate aspect of it, specifically the rights of the tenant: priority right to extend the term of the lease and the right to hold and use the leased property for the purpose of building a structure and its future exploitation (right to build). These rights currently have a significant importance due to the changes that are taking place in the Civil Code of the Russian Federation.
\end{abstract}

Ключевые слова: Юриспруденция, права арендатора, договор, аренда, земельный участок, новый срок, право застройки, владение, пользование, торги.

Keywords: Jurisprudence, tenant rights, agreement, lease, land, new term, right to build, ownership, use, negotiations.

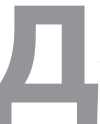

оговор аренды земельного участка в РФ регламентируется общими положениями о договоре аренды, содержащиеся в Гражданском кодексе РФ, Земельным кодексом РФ, Градостроительным кодексом РФ и другими нормативными правовыми актами. Во всех этих актах установлены как права, так и обязанности сторон договора аренды земельного участка. Однако хотелось бы остановиться на рассмотрении некоторых основных прав арендатора, которые возникают у него при заключении договора аренды земельного участка: преимущественное право на заключение договора аренды на новый срок и право владения и пользования чужим земельным участком в целях возведения на нем здания или сооружения и его последующей эксплуатации (право застройки).

Преимущественное право интересно представляется рассмотреть с точки зрения его реализации при заключении договора аренды по результатам проведения торгов (конкурсов, аукционов).

В силу п.п. 2, 3, 4 Постановления ВАС РФ от 17 ноября 2011 г. №73 «Об отдельных вопросах практики применения правил ГК РФ о договоре аренды» судам следует учитывать, что по смыслу части третьей пункта 1 статьи 621 ГК РФ преимущественным правом на заключение договора аренды обладает не только арендатор по действующему договору аренды, но и арендатор по договору, который был прекращен в течение года до заключения договора аренды с другим лицом или проведения торгов для заключения такого договора, при условии письменного уведомления арендодателя в порядке, установленном абзацем первым пункта 1 статьи 621 ГК РФ, о желании заключить новый договор аренды. Поскольку положения, предусматривающие обязательность проведения торгов, не лишают арендатора государственного или муниципального имущества принадлежащего ему в силу ст. 621 ГК РФ преимущественного права на заключение договора аренды на новый срок, такой арендатор вне зависимости от того, являлся ли он участником указанных торгов, вправе потребовать в суде перевода на себя прав и обязанностей по заключенному на торгах договору. Удовлетворению такого требования не препятствует отсутствие государственной регистрации договора аренды с победителем торгов. Судебный акт, которым иск о переводе прав и обязанностей удовлетворен, является основанием для внесения соответствующих записей в Единый государственный реестр прав на недвижимое имущество и сделок с ним. Вместе с тем, если арендодатель до заключения договора аренды с победителем торгов предложил арендатору заключить с ним договор аренды на условиях, предложенных победителем торгов, а арендатор отказался от заключения договора либо не принял этого предложения в названный в нем срок, суд отказывает такому арендатору в защите его преимущественного права (статья 10 ГК РФ). При этом если срок, в течение которого арендатор может принять данное 
предложение, не установлен арендодателем (статья 440 ГК РФ), он определяется с учетом абзаца второго пункта 5 статьи 448 ГК РФ, согласно которому договор аренды, заключаемый по результатам торгов, должен быть подписан сторонами не позднее двадцати дней или иного указанного в извещении срока после завершения торгов и оформления протокола. Если договор аренды с победителем торгов не заключен в связи с реализацией арендатором преимущественного права, правила пункта 5 статьи 448 ГК РФ о последствиях уклонения от заключения договора не применяются. Уплаченный победителем торгов задаток подлежит возврату (пункт 1 статьи 1102 ГК РФ). В этом случае, а также в случае удовлетворения судом требований арендатора о переводе прав и обязанностей по заключенному на торгах договору победитель торгов вправе требовать возмещения убытков, связанных с участием в торгах, если информация о наличии лица, обладающего преимущественным правом на заключение договора аренды, не была включена в извещение об их проведении. При этом судам следует учитывать, что отсутствие в извещении о проведении торгов такой информации не является основанием для признания торгов недействительными ${ }^{1}$.

В ст. 17.1. Федерального закона РФ от 26 июля 2006 г. №135-Ф3 «О защите конкуренции» закреплено аналогичное положение о преимущественном праве арендатора.

В данной ситуации прежний арендатор «разрушает» конструкцию договора аренды с победителем конкурса (аукциона) путем требования перевода прав нового арендатора на себя. Получается, что закрепленный законодателем порядок заключения договора аренды по конкурсу (аукциону) теряет юридический смысл ${ }^{2}$. Кроме того, данное правило предоставляет «недобросовестным чиновникам» передавать земельные участки в аренду без проведения торгов. Поэтому п. 1 ст. 621 ГК РФ целесообразно дополнить абз. 4: «Положения настоящего пункта не применяются, если арендодатель заключил договор аренды с другим лицом по результатам проведения торгов (конкурсов, аукционов) в отношении земельного участка, находящегося в государственной или муниципальной собственности».

Соответственно, необходимо внести изменения в Ф3 «О защите конкуренции».

Следующим немаловажным правом является право владения и пользования чужим земельным участком в целях возведения на нем здания или сооружения и его последующей эксплуатации (право застройки) ${ }^{3}$.

Согласно пункта 4 статьи 300, предложенного Проектом данного закона, собственник земельного участка сохраняет право распоряжения земельным участком, в отношении которого установлено право застройки. При этом не предусмотрена дальнейшая судьба арендатора, у которого земельный участок находится на праве пользования и владения, что дает возможность «недобросовестным собственникам»

\footnotetext{
1 Электронная справочная правовая система «Консультант плюс»

${ }^{2}$ См.: Kирилловых A. A. Преимущественное право арендатора в условиях нового порядка аренды федерального имущества // Право и экономика. 2007. № 11. С. 25.

${ }^{3}$ Проект Федерального закона № 47538-6 «О внесении изменений в части первую, вторую, третью и четвертую ГК РФ, а также в отдельные законодательные акты РФ» (далее-Проект)// Электронная справочная правовая система «Консультант Плюс».
}

прекратить такие отношения. В связи с чем, предлагается в п. 4 ст. 300 в Проект названного закона добавить следующий абзац: «Переход права собственности на переданный в пользование и владение земельный участок другому лицу не является основанием для изменения или расторжения договора об установлении права застройки».

Кроме того, в ст. 300.7 в Проекте абз. 2 п. 2 противоречит п. 4, что необходимо устранить законодателю до рассмотрения законопроекта ${ }^{4}$.

В соответствии со ст. 300.3 в Проекте «право застройки устанавливается бессрочно либо на срок, определенный в договоре об установлении права застройки. Такой срок не может быть менее тридцати и более ста лет». А ведь основная цель права застройки - возведение зданий, сооружений на земельном участке. Таким образом, данная норма дает возможность собственнику будущих зданий, сооружений не использовать данный земельный участок до 30 лет. По мнению автора, само право застройки нужно установить на срок, необходимый для возведения здания, сооружения (например, как это предусмотрено ст. 22 ЗК РФ для проведения изыскательских работ), а вот предоставить право пользования и владения застроенным земельным участком на срок не менее пятидесяти лет (как это было в первом варианте в Проекте). В связи с чем, предлагается ст. 300.3 изложить в следующей редакции: «300.3 Срок права застройки и права владения и пользования застроенным земельным участком 1. Право застройки устанавливается на срок, определенный в договоре об установлении права застройки. Такой срок не может быть более 5 лет. 2. Право пользования и владения застроенным земельным участком устанавливается бессрочно либо на срок, определенный в договоре об установлении права застройки. Такой срок не может быть менее пятидесяти и более ста лет. Право пользования и владения застроенным земельным участком, установленное на срок более ста лет, считается установленным на срок в сто лет».

Абсолютно новое законодательное закрепление 5 получил основополагающий принцип земельного законодательства - единство судьбы здания, сооружения с земельным участком. Если раньше данный принцип был закреплен в пользу собственника здания, сооружения (например, ст. 35

\footnotetext{
${ }^{4}$ Абз. 2 П. 2. ст. 300.7. ГК РФ в Проекте - Не допускается досрочное прекращение права застройки, если это право передано в ипотеку. П. 4 ст. 300.7. ГК РФ в Проекте - Право застройки может быть прекращено досрочно по требованию собственника земельного участка в случае, когда лицо, имеющее право застройки, имеет задолженность по внесению платы за право застройки в размере не менее чем двухгодичной платы, после направления лицу, имеющему право застройки, письменного предупреждения о необходимости устранения нарушения в разумный срок.

${ }^{5}$ П. 1 ст. 300.8 ГК РФ в Проекте - «При прекращении права застройки здания и сооружения, принадлежавшие лицу, имеющему право застройки, поступают в собственность собственника земельного участка, если иное не предусмотрено законом или договором об установлении права застройки».

Дублирующее положение содержится в п. 2 ст. 300 ГК РФ в Проекте, согласно которому «здания и сооружения, возведенные на основании права застройки, принадлежат лицу, имеющему право застройки, на праве собственности в течение срока действия права застройки. В установленных законом случаях договором может быть предусмотрено, что право собственности на возведенное здание или сооружение возникает у собственника земельного участка.
} 
DOI: $10.7256 / 1811-9018.2014 .12 .13317$

При цитировании этой статьи сноска на dоі обязательна

\section{Право и политика $12(180) \cdot 2014$}

ЗК РФ, ст. ст. 273, 552 ГК РФ), то сейчас (так как большая часть земельных участков находится в государственной и муниципальной собственности) право собственности приобретет на здание, сооружение соответственно государство, субъект РФ и муниципальное образование ${ }^{6}$. Таким образом, теряется веками развивающееся право собственности на земельный участок, так как с этого момента приобрести право собственности на земельный участок практически будет невозможно, а ведь это был один из основных вариантов возможности приобретения права собственности на земельный участок. А если эту проблему рассмотреть на примере многоквартирного дома, который был построен именно на условиях права застройки, получается, что собственники квартир не являются по сути дела собственниками, так как данный дом перейдет в собственность собственника земельного участка. А ведь идея право застройки, взятое из зарубежного законодательства (за исключением Германии), наоборот призвана передавать земельный участок после застройки именно собственнику здания, сооружения, а не призвана ставить цель - обладание застройкой.

Вместе с тем, многие авторы наоборот полагают, что «основное назначение права застройки - предоставить застройщику экономически необходимое, юридически прочное господство над чужим земельным участком. Застройщик, затрачивая большое количество ресурсов, надеется получить максимальные гарантии защиты своих интересов на всем протяжении пользования земельным участком и возведенным строением. Сопоставив основания для прекращения права аренды в сравнении с вещным правом застройки, становятся очевидны преимущества последнего. Право застройки предоставляет большую степень реальной юридической власти, столь необходимой застройщику. Недостатки права аренды в сравнении с правом застройки отражаются и на иных отношениях, сопровождающих возведение строения» 7 .

\section{Библиография:}

1. Гражданский кодекс РФ (часть вторая) от 26 января 1996 г. // Собрание законодательства РФ. - 1996. - № 5. - Ст. 410.

2. Земельный кодекс РФ от 25 октября 2001 г. // Собрание законодательства РФ. - 2001. - № 44. - Ст. 4147.

3. Федеральный закон от 26 июля 2006 г. № 135-ФЗ «О защите конкуренции» // Российская газета. - 2006. - 27 июля.

4. Проект Федерального закона № 47538-6 «О внесении изменений в части первую, вторую, третью и четвертую ГК РФ, а также в отдельные законодательные акты РФ» (далее - Проект)// Электронная справочная правовая система «Консультант Плюс».

5. Барановская И.Г. Некоторые вопросы применения норм о преимущественном праве арендатора на заключение договора аренды земельного участка на новый срок // Культура \& общество [Электронный ресурс]: Интернет-журнал МГУКИ/Моск.го.унив-т.культуры и искусств. - Электронный журнал, 2008. - Режим доступа: www.e-culture.ru.

6. Беляева О. А. Правовые проблемы аукционов и конкурсов. - М.: ИД «Юриспруденция», 2010. - 296 с.

7. Ершов О.Г., Полежаев О.А. Право застройки земельного участка или право аренды? // Электронная справочная правовая система «Консультант плюс».

8. Кирилловых А. А. Преимущественное право арендатора в условиях нового порядка аренды федерального имущества // Право и экономика. 2007. № 11.

9. Кузнецова Л. Преимущественное право аренды // Право и экономика. 2006. № 2.

10. Леонова Л. Аренда на новый срок // Домашний адвокат. 2004. № 1.

\section{References (transliterated):}

1. Baranovskaya I.G. Nekotorye voprosy primeneniya norm o preimushchestvennom prave arendatora na zaklyuchenie dogovora arendy zemel'nogo uchastka na novyi srok // Kul'tura \& obshchestvo [Elektronnyi resurs]: Internet-zhurnal MGUKI/Mosk.go.univ-t.kul'tury i iskusstv. - Elektronnyi zhurnal, 2008. - Rezhim dostupa: www.e-culture.ru.

2. Belyaeva O. A. Pravovye problemy auktsionov i konkursov. - M.: ID «Yurisprudentsiya», 2010. - $296 \mathrm{~s}$.

3. Ershov O.G., Polezhaev O.A. Pravo zastroiki zemel'nogo uchastka ili pravo arendy? // Elektronnaya spravochnaya pravovaya sistema «Konsul'tant plyus».

4. Kirillovykh A. A. Preimushchestvennoe pravo arendatora v usloviyakh novogo poryadka arendy federal'nogo imushchestva // Pravo i ekonomika. 2007. № 11.

5. Kuznetsova L. Preimushchestvennoe pravo arendy // Pravo i ekonomika. 2006. № 2.

6. Leonova L. Arenda na novyi srok // Domashnii advokat. 2004. № 1.

\footnotetext{
${ }^{6}$ При этом законодатель предупреждает, что данные нормы о праве застройки будут распространяться только на частные земельные участки, так как основания и порядок предоставления права застройки земельных участков, относящихся к государственной или муниципальной собственности, устанавливаются законом (п. 5 ст. 300 ГК РФ в Проекте). До сих пор непонятно, каким законом, когда в тексте статей прослеживаются ссылки на государственные и муниципальные земельные участки.
}

\footnotetext{
${ }^{7}$ Ериов О.Г., Полежсаев О.А. Право застройки земельного участка или право аренды? // Электронная справочная правовая система «Консультант плюс».
} 